\title{
Aircraft Engine Water Ingestion Generated by Tire Spray on Water-Contaminated Runways
}

\author{
Kaibin Zhao ${ }^{1, ~ a ~}$, Peiqing $\mathrm{Liu}^{2, \mathrm{~b}}$ and Qiulin Qu ${ }^{3, \mathrm{c}}$ \\ ${ }^{1,2,3}$ Beijing University of Aeronautics and Astronautics, Beijing, 100191, China

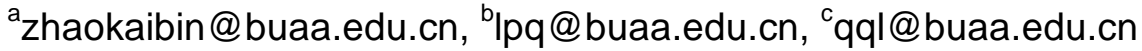

Keywords: Aircraft Engine Water Ingestion, Contaminated Runways, Chine Tire, SPH, DPM.

Abstract. Aircraft water ingestion tests on water-contaminated runways is of great significance in the civil aircraft airworthiness certification. It is a very complex strongly nonlinear multi-physics process involving tire-generated water spray and engine spray ingestion. An integrated simulation platform, which combines the Smooth Particle Hydrodynamics (SPH) method and the Discrete Phase Model (DPM) in a finite volume framework, is developed to predict the complex physical interactions and processes. The effects of nose gear chine tires are studied in alleviating or eliminating the engine spray ingestion problem.

\section{Introduction}

The tire water spray generated by aircraft taxiing on Water-Contaminated runways may be ingested by engine and cause engine surge, stall or even flameout. Therefore, the airworthiness requirements state that an airplane may not ingest hazardous quantities of water or slush into engines and Auxiliary Power Units (APUs) during taxiing, take-off and landing [1]. Many civil aircrafts [2,3] have completed the engine water ingestion tests before operating according to the airworthiness requirements. However, this kind of flight test entails a comparatively long time and high cost. Daugherty and Stubbs [4] conducted a series of experiments to measure the flow rate and trajectory of water spray generated by an aircraft tire operating on a flooded runway. However, the engine ingestion study was not conducted in their study. The ESDU [5] proposed an engineering estimation method to estimate the spray envelopes of the following plumes generated by aircraft-type tires running in water or slush. But the spray location is only roughly predicted and no information is obtained on water flow rates and engine water ingestion levels.

As to numerical simulation, Trapp and Oliveira [6] numerically simulated the water spray of the EMB-170 with deployed thrust reverser. Their results were in good agreement with the test results in computing the spray shape and the particle distribution around the EMB-170. Gooden [7] developed a method, named 'CR-Spray', for calculating the water spray generated by the tires and the resulting precipitation drag and engine ingestion. The method is based on the Lagrangian droplet trajectory calculation approach. The initial conditions for these trajectory calculations are obtained from the semi-empirical relations of the ESDU engineering method. Qu et al. [8] numerically simulated the water spray caused by a rolling airplane tire by the SPH method. They provided the detailed results of the whole spray process and the effects of tire forward speed and water film thickness on water spray. Zhao et al [9] proposed an integrated simulation platform combined the SPH method and the DPM model to predict the engine water ingestion level. The accuracy of the simulation platform is validated by the NASA experiment and the engine ingestion test of a regional jet with rear-mounted engines.

\section{Physical Process of the Tire Spray and the Subsequent Engine Water Ingestion}

Aircraft tire water spay and engine water ingestion is a very complex physical process, which contains several flow phenomena with different mechanics including deformation and fragmentation of water film, breakup of jet flow, formation of droplets, droplets motion in airflow field, etc. The entire process can be divided into two phases based on the different physical characteristics. The first phase is 
the formation of the water spray pattern due to the impact of a rolling tire on the water film. The second phase is the motion of a mass of droplets in the airflow field around the aircraft.

In the first phase, the tire rolling through the water film develops a wave because the water is washed away from the tire track. The resulting wave contains enough energy due to the large load and high taxiing speed of the tires, such that the water surface tension force can no longer keep the wave integrated and the water film starts to separate into a spray. In front of the tire a wave develops, ejecting the spray in forward and upward directions. Besides the tire a side wave develops, ejecting the spray sideways and upward. In the second phase, a mass of droplets move in the airflow field generated jointly by the aircraft's high speed taxiing and the air ingestion of engine intake. The trajectories of the droplets are complex due to the effects of gravity and aerodynamic forces. Ultimately, some droplets may be ingested into the engine and thus endanger the flight safety.

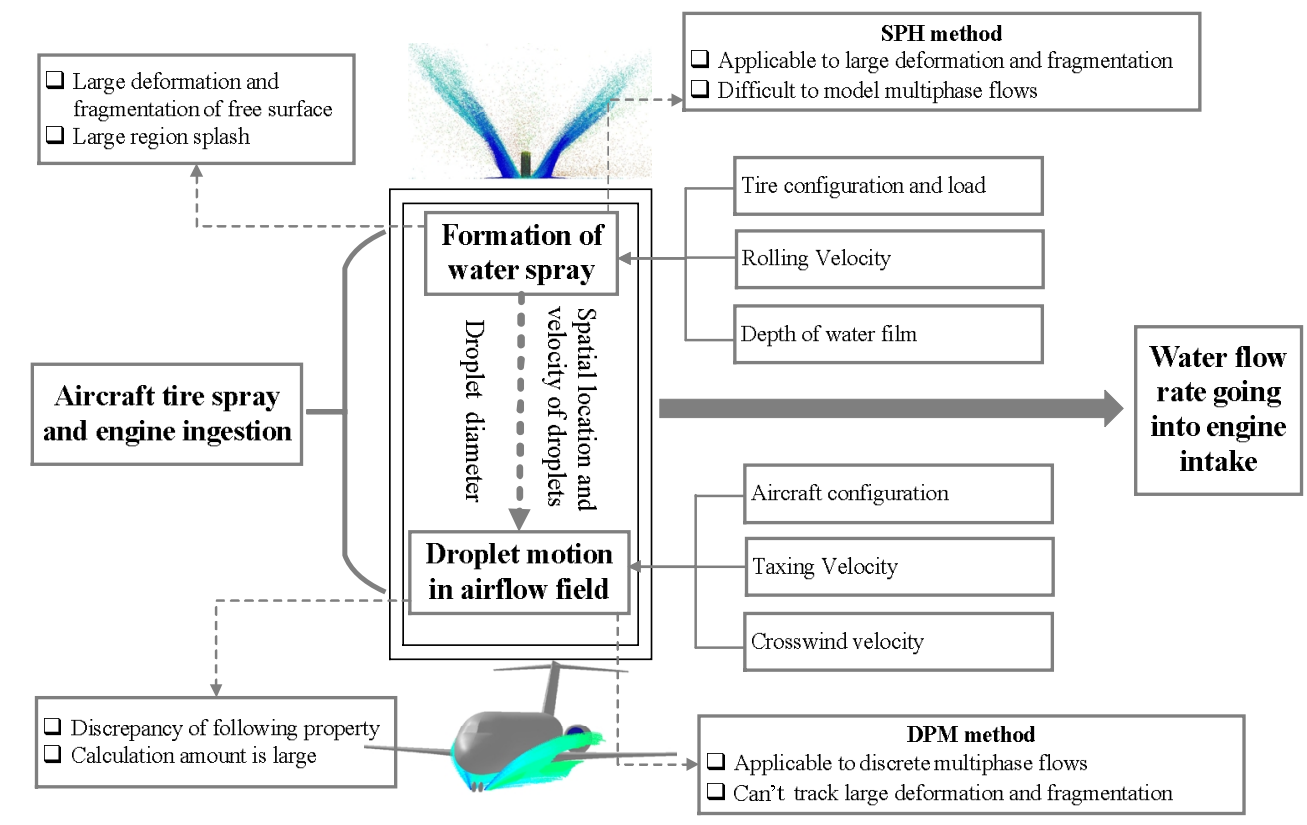

Fig. 1 Flow chart of the simulation platform for tire-generated water spray and engine water ingestion.

\section{Computational Methods}

As mentioned before, the process of tire-generated water spray and engine water ingestion during taxiing on water contaminated runways can be divided into two phases, the formation of water spay pattern and the droplet motion in the airflow field around the aircraft. So far, there has not been a sophisticated method to completely simulate the whole process of tire-generated water spray and engine water ingestion. In this study, we propose an original numerical simulation platform integrating the SPH method and the DPM method considering the different physical characteristics of the two phases. One of the important aspects of the present simulation platform is that we begin by accurately capturing the tire-generated water spray pattern with the SPH method, which is the key physical process for the subsequent engine water ingestion process and is usually neglected, simplified or has been based on empirical relations in previous work [8]. This part of the simulation platform provides the spatial locations and velocity vectors of all the droplets in the water spay pattern, which are used as the initial conditions of particles in the DPM method. Then, the second part of the simulation platform predicts the trajectories of the droplets in the airflow field using the DPM method. Finally, the simulation platform evaluates the water flow rate going into the engine intakes. The flow chart of the simulation platform for tire water spray and engine water ingestion is shown in Fig. 1. 


\section{The Effects of Chine Tire in Alleviating Aircraft Engine Water Ingestion}

A chine tire is one constructed with an extending lip molded into the sidewall just above the tread. This type of tire is generally designed to deflect water and slush to the side and away from intakes on aft-fuselage mounted jet engines. Such tires are currently in service on several commercial jet transports. Ingestion problems are more usually associated with spray from the nose wheel rather than the main wheels. We researched the effects of nose gear chine tires in alleviating or eliminating the engine spray ingestion problem on a regional jet with rear-mounted engines and chose an optimized chine profile. Fig. 2 and Fig. 3 show the SPH simulation results for the water spray of the original tire and the optimized chine tire. It indicates the chine located at the negative $\mathrm{Y}$-axis direction can fairly alleviates the water spray.

A mass of droplets comprising the tire water spray move in the airflow field generated jointly by the aircraft's high speed taxiing and the air ingestion of engine intake. A part of droplets may be ingested by engine intake and endanger the flight safety. The droplets trajectory simulation results by the simulation platform are shown as Fig. 4 and Fig. 5. As can be seen from the figures, the droplets trajectory of the original tire spray just cover the engine intake and most of the droplets are ingested by engine. Obviously, it does not meet the airworthiness requirements. Due to the deflecting water effect, the droplets trajectory of the optimized chine tire spray is deflected to the side of aircraft and away of engine intake. The engine doesn't ingest water and definitely can meet the airworthiness requirements. Fig. 6 shows the comparison of the DPM concentration of three vertical planes after nose tire between the original tire water spray and optimized chine tire spray trajectory around aircraft. It can be seen that the engine ingest no spray water generated by optimized nose gear chine tire. It indicates that the optimized nose gear chine tire have the effect of alleviating the regional jet engine water ingestion.

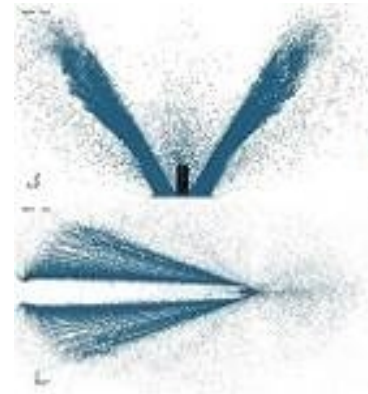

Fig. 2 Water spray of original tire. $(V=55 \mathrm{~m} / \mathrm{s}$, $\mathrm{H}=16 \mathrm{~mm}$ )

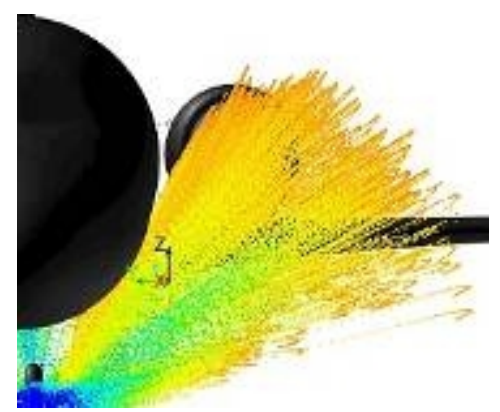

Fig. 4 Original tire spray trajectory in aircraft flowfield. $(\mathrm{V}=55 \mathrm{~m} / \mathrm{s}, \mathrm{H}=16 \mathrm{~mm})$

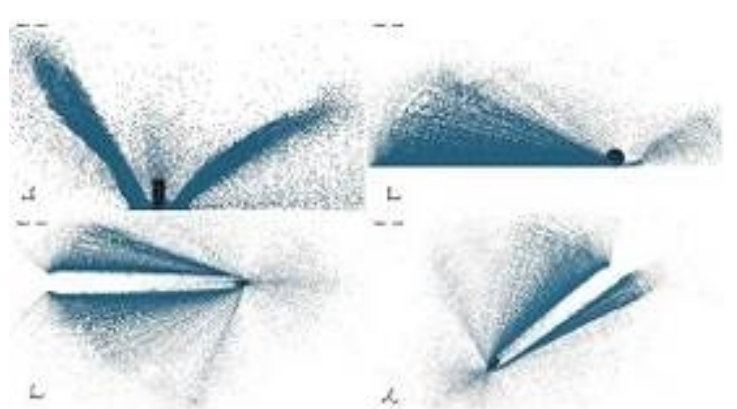

Fig. 3 Water spray of optimized chine tire. $(\mathrm{V}=55 \mathrm{~m} / \mathrm{s}, \mathrm{H}=\mathbf{1 6} \mathrm{mm})$

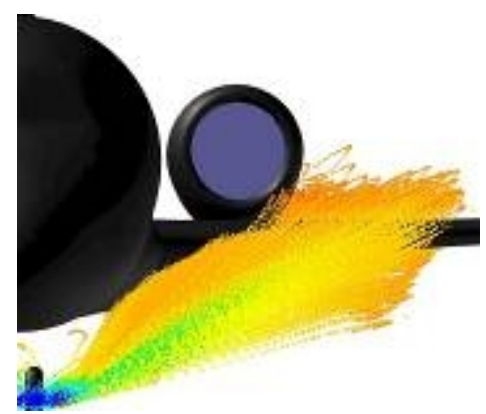

Fig. 5 Optimized chine tire spray trajectory in aircraft flowfield. ( $\mathrm{V}=55 \mathrm{~m} / \mathrm{s}, \mathrm{H}=\mathbf{1 6} \mathrm{mm}$ )

\section{Conclusions}

An integrated simulation platform, which combines the Smooth Particle Hydrodynamics (SPH) method and the Discrete Phase Model (DPM) in a finite volume framework, is developed to predict the complex physical interactions and processes of the aircraft tire spray and engine water ingestion. The effects of the chine tire in alleviating aircraft engine water ingestion is studied by this simulation platform. And an optimized nose gear chine tire is proposed. The simulation results indicates the chine 
tire can eliminate the engine water ingestion generated by the nose gear tire spray on water-contaminated runways.

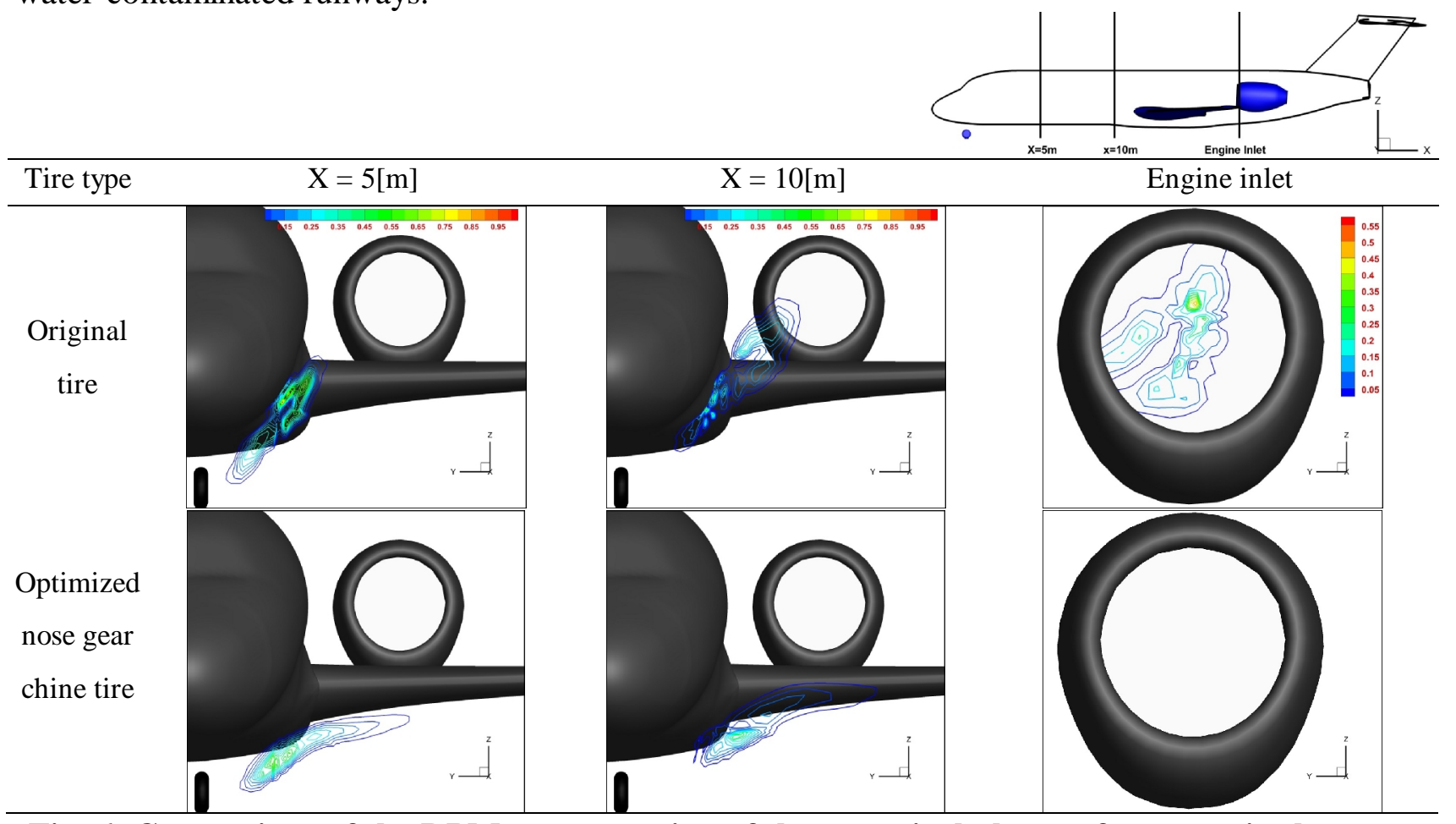

Fig. 6 Comparison of the DPM concentration of three vertical planes after nose tire between the original tire water spray and optimized chine tire spray trajectory around aircraft.

\section{References}

[1]. JAA."Supplementary performance information for take-off from wet runways and for operations on runways contaminated by standing water, slush, loose snow, compacted snow or ic," JAR-25, AMJ 25X1591, 1993.

[2]https://www.flightglobal.com/news/articles/pictures-comac-arj21-undergoes-water-ingestion-test$373543 /$

[3]. Information on http://www.boeing.com/features/2017/01/max-water-spray-testing-01-17.page.

[4]. R. H Daugherty, and S. M. Stubbs. "Measurements of flow rate and trajectory of aircraft tire-generated water spray," NASA TP-2718, 1987.

[5]. ESDU. "Estimation of spray patterns generated from the sides of aircraft tyres running in water or slush," ESDU 83042. London, Apr. 1998.

[6]. L. G. Trapp, and G. L. Oliveira. "Aircraft thrust reverser cascade configuration evaluation through CFD," American Institute of Aeronautics \& Astronautics, 41st Aerospace Sciences Meeting and Exhibit, Reno, Nevada. AIAA-2003-0723, Jan. 2003.

[7]. Q. Qu, F. Zhang, P. Liu, and R. K. Agarwal. "Numerical Simulation of Water Spray Caused by a Rolling Airplane Tire," Journal of Aircraft, Vol. 53, No. 1, 2016, pp. 182-188.

[8]. J. H. M. Gooden. "Engine ingestion as a result of crosswind during take-offs from water contaminated runways," NLR-TP-2013-201, Amsterdam, Netherlands, Jun. 2013.

[9] K. Zhao, P. Liu, and Q. Qu. "Numerical Simulation of Aircraft Tire-Generated Spray and Engine Ingestion on Flooded Runways," [J]. Journal of Aircraft, (online): April. 2017. 